\title{
Influence of educational level on test and treatment for incident hypothyroidism
}

Møllehave, Line Tang; Jacobsen, Rikke Kart; Linneberg, Allan; Skaaby, Tea; Knudsen, Nils; Jørgensen, Torben; Kảrhus, Line Lund; Kriegbaum, Margit; Grand, Mia Klinten; Siersma, Volkert

Total number of authors:

17

Published in:

Clinical Endocrinology

Link to article, DOI:

10.1111/cen. 14429

Publication date:

2021

Document Version

Peer reviewed version

Link back to DTU Orbit

Citation (APA):

Møllehave, L. T., Jacobsen, R. K., Linneberg, A., Skaaby, T., Knudsen, N., Jørgensen, T., Kårhus, L. L., Kriegbaum, M., Grand, M. K., Siersma, V., Lind, B., Andersen, C. L., Nygaard, B., Medici, B. B., Pedersen, I. B., Ravn-Haren, G., \& Thuesen, B. H. (2021). Influence of educational level on test and treatment for incident hypothyroidism. Clinical Endocrinology, 94(6), 1025-1034. https://doi.org/10.1111/cen.14429

\section{General rights}

Copyright and moral rights for the publications made accessible in the public portal are retained by the authors and/or other copyright owners and it is a condition of accessing publications that users recognise and abide by the legal requirements associated with these rights.

- Users may download and print one copy of any publication from the public portal for the purpose of private study or research.

- You may not further distribute the material or use it for any profit-making activity or commercial gain

- You may freely distribute the URL identifying the publication in the public portal 
MRS LINE TANG M ØLLEHAVE (Orcid ID : 0000-0001-7116-9346)

Article type $\quad: 1$ Original Article - UK, Europe

Influence of educational level on test and treatment for incident hypothyroidism

Running title: SES, test, treatment for hypothyroidism

Line Tang Møllehave, $\mathrm{MSc}^{1}$

Rikke Kart Jacobsen, $\mathrm{MSc}^{1}$

Allan Linneberg, MD PhD ${ }^{1,2}$

Tea Skaaby, MD PhD ${ }^{1}$

Nils Knudsen, PhD DMSc ${ }^{3}$

Torben Jørgensen, $\mathrm{DMSc}^{1,4,5}$

Line Lund Kårhus, MD PhD ${ }^{1}$

Margit Kriegbaum, $\mathrm{PhD}^{6}$

Mia Klinten Grand, $\mathrm{PhD}^{6}$

Volkert Siersma, $\mathrm{PhD}^{6}$

Bent Lind, DMSc ${ }^{7}$

Christen Lykkegaard Andersen, $\mathrm{PhD} \mathrm{DMSc}^{6,8}$

Birte Nygaard, MD PhD ${ }^{9}$

Bjarke Borregaard Medici, MD PhD ${ }^{9}$

Inge Bülow Pedersen, PhD DMSc ${ }^{10}$

Gitte Ravn-Haren, $\mathrm{PhD}^{11}$

Betina Heinsbæk Thuesen, $\mathrm{PhD}^{1}$

This article has been accepted for publication and undergone full peer review but has not been through the copyediting, typesetting, pagination and proofreading process, which may lead to differences between this version and the Version of Record. Please cite this article as doi: $\underline{10.1111 / C E N .14429}$

This article is protected by copyright. All rights reserved 
${ }^{1}$ Center for Clinical Research and Prevention, Bispebjerg and Frederiksberg Hospital, Capital Region, Denmark

2 Department of Clinical Medicine, Faculty of Health and Medical Sciences, University of Copenhagen, Denmark

${ }^{3}$ Department of Endocrinology, Bispebjerg University Hospital, University of Copenhagen, Denmark

${ }^{4}$ Department of Public Health, Faculty of Health and Medical Sciences, University of Copenhagen, Copenhagen, Denmark.

${ }^{5}$ Faculty of Medicine, Aalborg University, Aalborg, Denmark

${ }^{6}$ Research Unit for General Practice and Section of General Practice, Department of Public Health, University of Copenhagen, Denmark

${ }^{7}$ Department of Clinical Biochemistry, Copenhagen University Hospital Hvidovre, Hvidovre, Denmark ${ }^{8}$ Department of Hematology, Rigshospitalet, Copenhagen, Denmark

${ }_{9}^{9}$ Department of Endocrinology, Herlev and Gentofte hospital, University of Copenhagen, Denmark

${ }^{10}$ Department of Endocrinology and Medicine, Aalborg University Hospital, Aalborg, Denmark

${ }^{11}$ Division of Diet, Disease Prevention and Toxicology, National Food Institute, Technical University of Denmark, Denmark

Correspondence:

Line Tang Møllehave, Center for Clinical Research and Prevention, Bispebjerg and Frederiksberg Hospital, Capital Region, Frederiksberg Hospital, Hovedvejen, Entrance 5, Nordre Fasanvej 57, DK-2000 Frederiksberg, Denmark. TIf: +45 38633275. E-mail: line.tang.moellehave@regionh.dk.

\section{ACKNOWLEDGEMENTS}

The authors acknowledge the crucial work performed by the secretariat of The Public Health Database at the Department of Public Health at the University of Copenhagen in regard to operating and establishing project data. The authors acknowledge support from the DanThyr steering group. The study received financial support from Helsefonden, grant no. 19-B-0379 and the European Union's Horizon 2020 research and innovation program under grant agreement no. 634453. The funders had no role in study design, data collection and analysis, decision to publish, or preparation of the manuscript.

\section{DATA AVAILABLILITY}

This article is protected by copyright. All rights reserved 
The data that support the findings of this study are available from Statistics Denmark. Restrictions apply to the availability of these data, which were used under license for this study. Data are available for university-based Danish scientific organisations authorized to work with data within Statistics Denmark and such organisation can provide access to individual scientists inside and outside of Denmark with the permission of Statistics Denmark and the Danish Data Protection Agency.

Words in summary: 248

Words in manuscript: 3,098

Figures: 3

Tables: 3

This article is protected by copyright. All rights reserved 


\section{SUMMARY}

Objective: The prevalence of hypothyroidism is not expected to differ by socioeconomic factors. However, the decision to test and initiate treatment may differ. We aimed to examine whether educational level influences the probability of thyroid stimulation hormone (TSH)-measurement and initiation of levothyroxine treatment.

Design: Citizens in the greater Copenhagen Area during 2001-2015 were included. Individual-level data on educational level, diagnoses, GP-contact, TSH-measurement, and medication were derived from administrative and health care registers. The relative risks (RR) between educational levels of annual TSHmeasurement and treatment initiation following a TSH-measurement were analyzed in Poisson regression models with generalized estimation equations.

Results: A TSH-measurement was performed in 19\% of 9,390,052 person years. The probability of TSHmeasurement was higher with short ( $R R 1.16(95 \% \mathrm{Cl} 1.15-1.16))$ and medium (RR $1.11(95 \% \mathrm{Cl} 1.06-1.12)$ ) compared with long education.

Treatment was initiated after $0.8 \%$ of $2,049,888 \mathrm{TSH}$-measurements. For TSH $<5$ mIU/L RR for treatment initiation ranged between $0.47(95 \% \mathrm{Cl} 0.39-0.57)$ and $0.78(95 \% \mathrm{Cl} 0.67-0.91)$ for short and medium compared with long education. For TSH 5-10 mIU/L there was no statistically significant difference. For $\mathrm{TSH}>10 \mathrm{mIU} / \mathrm{L}$ RR was $1.07(95 \% \mathrm{Cl} 1.02-1.12)$ for short and $1.08(95 \% \mathrm{Cl} 1.03-1.13)$ for medium compared with long education.

Conclusion: The probability of TSH-measurement was higher with shorter education and the probability of treatment initiation with TSH $>10 \mathrm{mIU} / \mathrm{L}$ was marginally higher with short-medium education compared with long education. However, the probability of treatment initiation with $\mathrm{TSH}<5 \mathrm{mIU} / \mathrm{L}$, i.e. treatment incongruous with guidelines, was substantially higher in persons with long education.

Keywords: socioeconomic factors, hypothyroidism, thyroid function tests, levothyroxine

This article is protected by copyright. All rights reserved 


\section{INTRODUCTION}

Social inequality in health care explains a large proportion of the inequality in health and life expectancy. ${ }^{1}$ Social inequality in treatment is observed for several diseases in Denmark and persists despite universal free health care. ${ }^{2}$ Most tests and treatments for hypothyroidism are conducted at the general practitioner (GP). ${ }^{3}$ Hypothyroidism is common with a prevalence of $1-2 \%$ in iodinereplete populations, ${ }^{4}$ and treatment with levothyroxine has doubled during the two past decades. ${ }^{5}$ Nevertheless, few studies have examined social inequality in test and treatment for hypothyroidism. Elucidation of the influence of socioeconomic status on test and treatment is essential in the process towards equity in health.

Social inequality in disease is divided into two categories: inequality in the risk of disease and inequality in treatment. There is likely to be little socioeconomic difference in the risk of hypothyroidism because both iodine intake ${ }^{6,7}$ and subclinical hypothyroidism ${ }^{8}$ have been found to be independent of socioeconomic factors in areas with efficient iodine fortification and iodine repletion, respectively. However, the decision to test and treat for hypothyroidism partly rely on factors that may increase the risk of social inequality. Symptoms of hypothyroidism are not objectively measured, occur frequently in euthyroid persons, and have little diagnostic power for hypothyroidism. ${ }^{9}$ The European Thyroid Association (ETA) guidelines recommend treatment with levothyroxine for overt hypothyroidism (high s-TSH and low s-T4) in patients $<70$ years and for subclinical hypothyroidism (high sTSH and normal s-T4) with symptoms in patients $<65$ years ${ }^{10}$ but the threshold for treatment initiation is debated. ${ }^{11,12}$

In the greater Copenhagen Area incident overt hypothyroidism increased by $30 \%$ after iodine fortification in $2000 .{ }^{13}$ Concurrently, incident treatment for hypothyroidism increased by $75 \%$ from 2000 until 2010, where it plateaued. ${ }^{5}$ This gap is primarily due to treatment initiation at lower TSHthresholds and secondarily due to more tests of TSH. ${ }^{14}$ However, it is not known whether the increase in tests and decrease in threshold for treatment are equal across socioeconomic groups or more prominent in some groups.

Educational level will be utilized as the measure of socioeconomic status in this study because it is an underlying determinant for other socioeconomic measures. ${ }^{15}$ Furthermore, education may make persons "more able to communicate with and access appropriate health services". ${ }^{16}$

This article is protected by copyright. All rights reserved 
The primary aim of this study was to examine whether educational level is associated with TSHmeasurement and initiation of levothyroxine treatment. Secondarily, we aimed to analyze changes in these potential relations during 2001-2015.

\section{MATERIALS AND METHODS}

\section{Study populations}

We included all citizens aged $\geq 25$ in the Copenhagen Municipality and the former Copenhagen County on the $1^{\text {st }}$ of January for each year 2001-2015.

We examined annually whether a TSH-measurement was conducted after a GP-contact as part of a medical examination for incident disease. Observations were excluded if there was a) current or previous diagnosis of hyperthyroidism (ICD-10: DE05.0-9), thyroid cancer (ICD-10: DC73.9), or pituitary disease (ICD-10: DE23.0-9); b) a redeemed prescription of thyroid-interfering drugs within six previous months (amiodarone (ATC: C01BD01), lithium (ATC: N05AN01), propylthiouracil (ATC: H03BA02), thiamazole (ATC: H03BB01), carbimazole (ATC: H03BB01), monoclonal antibodies (ATC: L01XC), and protein kinase inhibitors (ATC: L01XE)), c) a redeemed prescription of levothyroxine (ATC: H03AA) within three previous years, or; d) a birth or abortion (ICD-10: DO03.0-9) within 12 months before or after. ${ }^{14}$ Observations with unknown educational level were excluded.

Likewise, we examined whether incident treatment was initiated after a TSH-measurement requested by a GP. TSH-measurements were excluded if they met one of the criteria a)-d) described above. If two TSHmeasurements were performed within four months only the last was included as the measurements were regarded part of the same examination. ${ }^{14}$ Finally, TSH-measurements with missing TSH-values or unknown educational level were excluded.

The flow of in- and excluded observations is illustrated in Figure 1.

\section{Data sources}

All GPs in the Copenhagen Municipality and former Copenhagen County were serviced by one laboratory during 2000-2015. The Copenhagen Primary Care Laboratory (CopLab) Database contains results from all tests and analyses performed, ${ }^{17}$ and we utilized data on TSH-measurements. Furthermore, we utilized individual-level data from nationwide administrative population and healthcare registers. Registries at Statistics Denmark contain information on educational level, ${ }^{18}$ municipality of residence, age, and sex ${ }^{19}$ 
and is updated annually. The Danish National Patient Register (NPR) contains diagnoses for all in- and outpatient hospital contacts since 1977. ${ }^{20}$ The Danish National Prescription Registry (DNPR) contains records of all redeemed prescriptions since 1995, ${ }^{21}$ and The National Health Service Register contains records of all contacts to GPs since $1990 .{ }^{22}$ Individual-level linkage between CopLab data and nationwide registers is possible via the unique civil registration number assigned to all Danish citizens. ${ }^{19}$

Ethical and data handling approval was obtained at the Faculty of Health Science, University of Copenhagen (case no. 514-0244/18-3000).

\section{Outcome variables}

TSH-measurement was defined as at least one TSH-measurement in a year conducted within 30 days of a GP-contact. TSH-measurement was recorded for the year of the GP-contact closest to the measurement. Treatment initiation was defined as a redeemed prescription of levothyroxine (ATC: H03AA) within six months following a TSH-measurement. Treatment initiation was recorded for the TSH-measurement closest to a first redeemed prescription.

\section{Education, age, sex, municipality, and comorbidities}

Highest attained educational level was divided into three categories according to the International Standard Classification of Education (ICSED) levels: short education (primary or upper secondary education), medium education ( $>4$ years; vocational education), and long education ( $\geq 4$ years: bachelor's or master's degree or short-cycle higher education). Information on age, sex and municipality of residence was obtained from the Civil Registration System. The Charlson comorbidity index (CCI) as updated in $2011^{23,24}$ was calculated for each observation as a cumulative weighted score (maximum 24) from the number and severity of comorbid conditions. Primary and secondary diagnoses during the two previous years were derived from the NPR, and the CCI was calculated using a SAS macro (developed by Ken Turner and Charles Burchill). ${ }^{25}$ The $\mathrm{CCl}$ was classified into 0 (none) and $\geq 1$. For each observation, all variables were defined annually.

\section{TSH analyses}

TSH measurements were performed in one laboratory and was determined in serum by the commercially available ADVIA Centaur/CentaurXP method (Bayer/ Siemens, Tarrytown, NY) with a coefficient of variation of $4,9-6,3 \%$. The method has been described in more detail previously. ${ }^{14}$ The normal range of TSH-measurements reported to GPs was $0.2-5.0 \mathrm{mIU} / \mathrm{l}$. Observations outside the reported lower $(<0.02$ $\mathrm{mIU} / \mathrm{L}$ ) and upper (>135 or $>150 \mathrm{mIU} / \mathrm{L}$ ) detection limit were included with their value set to the value of the limit. ${ }^{14}$

This article is protected by copyright. All rights reserved 


\section{Statistical analyses}

Population characteristics are presented for the total population and stratified by educational level. Poisson regression with robust standard errors was applied to assess the relative risk (RR) and 95\% confidence intervals $(95 \% \mathrm{Cl})$ for the associations between educational level and TSH-measurement and treatment initiation. Because each person may be found in the datasets more than once (once every year and with more than one TSH-measurement), one person constitutes a cluster, and thus Generalized Estimating Equations were applied to correct for clusters of correlated observations. The independent correlation structure provided the best fit evaluated by the QIC-value. Dose-response relationships were assessed by testing the linear effect of the ordinal variable. Effect measure modifications were assessed by testing the interaction terms and the joint effects derived from the models are presented.

Analyses of the association between educational level and TSH-measurement within a person year was adjusted for sex, age, $\mathrm{CCl}$, and calendar year. The effect of calendar year (split into five 3-year levels) was tested by adding the interaction with educational level to the model one pair at a time. In sensitivity analyses the model was further adjusted for the mediator 'number of GP-contacts within a year'.

Analyses of the association between educational level and treatment initiation were adjusted for sex, age, $\mathrm{CCl}$, TSH-level, calendar year, and the interaction between educational level and TSH-level. The effect of calendar year (split into five 3-year levels) was explored by adding the 3-way interaction between educational level, TSH-level, and calendar year.

Analyses were performed in SAS, version 9.4 (SAS Institute Inc, Cary, NC, USA) and statistical significance defined as $p<0.05$.

\section{RESULTS}

Descriptive statistics of characteristics of the populations are presented according to educational level in Table 1. Persons with shorter education had higher age and more frequently had a $\mathrm{CCl} \geq 1$. The number of GP-contacts within one year was higher with shorter education. The level of TSH did not differ markedly between educational levels (Table 1). The number of person years increased during the study period in the group with longer education but not in the other groups. The number of TSH-measurements increased during the study period for all educational levels but relatively more in the group with longer education (Table 1). This is partly explained by more persons with long education in the greater Copenhagen Area during the study period (Supplementary Table S1).

\section{TSH-measurement}


A TSH-measurement was performed in $19 \%(1,805,300 / 9,390,052)$ of the person years. The probability of TSH-measurement was higher in persons with short and medium education, $\mathrm{RR} 1.16(95 \% \mathrm{Cl} 1.15-1.16)$ and RR 1.11 (95\% Cl 1.06-1.12), respectively, compared with long education (Table 2) with a clear doseresponse relationship ( $p$ for trend $<0.001$ ).

There was a statistically significant effect of the interaction between educational level and calendar year. During the study period, the RR for TSH-measurement increased for both short and medium education compared with long education in the same year and fell back to approximately the same level (Figure 2).

When adjusting for the number of GP-contacts per year the estimates decreased marginally.

Supplementary analyses found a higher probability of TSH-measurement with higher age, in women, with lower income, and a marginally higher probability of TSH-measurement in persons living without a partner (Supplementary Material S2 and Table S3).

\section{Treatment initiation}

Treatment was initiated after $0.8 \%(16,992 / 2,049,888)$ of the TSH-measurements. The probability of treatment initiation was lower following TSH-measurements in persons with short or medium education compared with long education for TSH $<0.4,0.4-2.5$, and 2.5-5 mIU/L with RR ranging between 0.47 $(95 \% \mathrm{Cl} 0.39-0.57)$ and $0.78(95 \% \mathrm{Cl} 0.67-0.91)$. There was no difference in the probability of treatment initiation between the educational levels with TSH 5-10 mIU/L and a marginally higher probability of treatment initiations in persons with short or medium education compared with long education for TSH $>10 \mathrm{mIU} / \mathrm{L}$ with RR $1.07(95 \% \mathrm{Cl} 1.02-1.12)$ and $1.08(95 \% \mathrm{Cl} 1.03-1.13)$ for short and medium education, respectively. The probability of treatment initiation was similar for short and medium educational level for all TSH-levels (Table 3).

There was a statistically significant effect of the 3-way interaction between educational level, TSH-level, and calendar year: For TSH $<0.4$ and 2.5-5 mIU/L, the probability of treatment initiation was consistently lower for persons with short or medium education compared with long education during the study period. For TSH 0.4-2.5 mIU/L, the probability of treatment initiation for short and medium education was higher in 2001-2003 and lower from 2007 compared with long education. For TSH 5-10 and >10 mIU/L, the probability of treatment initiation was lower and higher, respectively, for short and medium education before 2006 and largely similar to the probability for long education after 2007 (Figure 3).

This article is protected by copyright. All rights reserved 
Supplementary analyses found a higher probability of treatment initiation with lower age, in women, and a marginally higher probability of treatment initiation in persons living with a partner for all levels of TSH. The probability of treatment initiation was higher with higher income for TSH $<0.4$ and $2.5-5 \mathrm{mIU} / \mathrm{L}$ while there was no difference for TSH 0.4-2.5 and >5 mIU/L (Supplementary Material S2 and Table S4-S7).

\section{DISCUSSION}

The current knowledge of socioeconomic inequality in tests and treatments of hypothyroidism is limited despite frequent and increasing use of both TSH-measurements and levothyroxine treatment. In this first large population-based register study on the topic, we found that the probability of a TSH-measurement within a year was highest in persons with shorter education. However, the probability of treatment initiation was highest following TSH-measurements in persons with longer education for lower levels of TSH and slightly higher for higher levels of TSH.

Contact with the GP is a necessary first step before thyroid function test and treatment. In additional analyses, we found a 1-3\% higher probability of having one or more GP-contacts within a year for short and medium education compared with long education (Supplementary Material S1 and Table S2). This indicates that social inequality does not markedly influence this step in health care for hypothyroidism.

We identified only one previous study on the association between socioeconomic characteristics and treatment for hypothyroidism. In a population of 14,590 civil servants from six Brazilian cities, the frequency of hypothyroidism defined by elevated TSH and/or prevalent levothyroxine use did not differ by educational level or income. But interestingly, the use of levothyroxine was significantly associated with higher income with an odds ratio of 3.34 (1.48-7.57) for medium income and 3.07 (1.01-9.38) for high income compared with low income after adjustment. ${ }^{26}$ However, their data does not reveal if this is due to differences in tests, treatments, or both. Furthermore, the mechanisms underlying the effect of income may differ between the Danish and the Brazilian healthcare systems.

Educational level was chosen as the socioeconomic exposure because it is a determinant for other sociodemographic factors. ${ }^{15}$ Measurement of educational level attempts to capture knowledge, cognitive skills, and analytical abilities, ${ }^{16}$ which may influence the acquisition of health information and interaction with GPs and thus the decision to test and treat. Income captures material resources available to the individual, ${ }^{16}$ which is less relevant in a Danish context with free universal health care and a relatively low

This article is protected by copyright. All rights reserved 
cost of levothyroxine treatment (EUR 35.5/user/year in 2015 prices). ${ }^{27}$ Yet, similar results were found for income in supplementary analyses.

It is interesting to note that among the lower levels of TSH, short and medium education had a lower probability of treatment initiation compared with long education. Treatment initiation with TSH $<5 \mathrm{mIU} / \mathrm{L}$ is considered inappropriate in this patient group (excluding patients with previous thyroid cancer and plans of pregnancy) according to guidelines. ${ }^{10}$ In a survey among 539 physicians, $46 \%$ reported patient's requests for tests and treatment as a barrier to proper management of hypothyroidism only surpassed by patient non-adherence (70\%). Patients requested e.g. adjusting thyroid hormone dose based on symptoms when biochemically euthyroid and maintaining TSH below the reference range. Physicians receiving these requests were more likely to execute this practice. ${ }^{28}$ It may be speculated that persons with long education are more prone to request treatments discrepant with guidelines or decline indicated treatments.

Treatment initiation with TSH within the reference range may for few cases be due to treatment for goiter or subacute thyroiditis. Moreover, levothyroxine is occasionally used to treat depression, overweight, tiredness or other symptoms of hypothyroidism in euthyroid persons despite recommendations. This practice is hypothesized to be more frequent in persons with long education due to requests and/or an increased awareness in this group of discussions of subclinical hypothyroidism.

Even though the absolute number of persons initiating treatment with suppressed TSH is low, the implications are serious as overtreatment of hypothyroidism is associated with an increased risk of atrial fibrillation, osteoporotic fractures, ${ }^{29}$ and all-cause mortality. ${ }^{30}$

Among subjects with high levels of TSH, short and medium education had a higher probability of treatment initiation compared with long education. Part of this difference may be explained by subclinical hypothyroidism for which the ETA recommends treatment in persons $\leq 70$ years and consideration of treatment in person $>70$ years with clear symptoms of hypothyroidism or high vascular risk. ${ }^{10}$ Symptoms and vascular risk factors are more frequent with shorter education ${ }^{31}$ and may affect the probability of treatment initiation as we were unable to adjust for this.

Through the study period, the inequality in TSH-measurements rose and fell. The development in the inequality in treatment initiation differed between levels of TSH: For TSH $<0.4 \mathrm{mIU} / \mathrm{L}$ and $2.5-5 \mathrm{mIU} / \mathrm{L}$ the inequality remained relatively constant while for TSH 0.4-2.5 mIU/L the inequality changed direction. Both TSH 5-10 mIU/L and >10 mIU/L approached no inequality after 2006. This may be driven by the

This article is protected by copyright. All rights reserved 
implementation of mandatory measurement of thyroid peroxidase (TPO)-antibodies if s-TSH was $>5$ $\mathrm{mIU} / \mathrm{L}$ and free thyroxine was within the reference range from December $2006 .{ }^{14}$ In contrast with symptoms and vascular risk factors, TPO-antibodies are not assumed to be associated with educational level. Treatment decisions for subclinical hypothyroidism based on TPO-antibodies (despite this not being recommended by the $\mathrm{ETA}^{10}$ ) may thus minimize educational differences.

\section{Strengths and limitations}

The main strength of this study is the large sample size and utilization of individual-level register data of good validity ${ }^{32}$ along with well-documented laboratory data from GPs, which is rarely available. There is limited risk of confounding by geographic differences in access to health care because the whole population lives in the greater Copenhagen Area. It is a limitation that data were not available for symptoms, fT4, fT3, and anti-TPO to ascertain the specific indication for TSH-measurement and treatment. Somatic symptoms are more frequent with lower educational level ${ }^{31}$ and unspecific symptoms such as tiredness may influence the decision to measure TSH and/or initiate treatment. Although, somatic symptoms are closely associated with the presence of comorbidities ${ }^{31}$ they may not be sufficiently adjusted for through the $\mathrm{CCl}$. We were unable to include data on smoking. Smoking is more frequent with short education and increases the risk of hypothyroidism ${ }^{33}$, thus, the GP's knowledge of smoking status may be a confounder in the association between educational level and TSH-measurement. Smoking will be reflected in the TSH-level ${ }^{34}$ and should therefore not further influence the decision to initiate treatment.

In conclusion, the results indicate that the probability of TSH-measurement is consistently higher with shorter education. The probability of treatment initiation with high levels of TSH was marginally higher with short and medium education compared with long education. However, these inequalities approached 0 during the study period and are thus of less concern. The probability of inappropriate treatment initiation with low or normal TSH-levels is substantially higher in persons with long education, and these inequalities are of concern as they persist throughout the study period. This warrants further studies to elucidate the motivation for treatment initiation with low and normal TSH to prevent overtreatment. Further, this is only the second study of inequalities in test and treatment of hypothyroidism, and this should be repeated in populations with different health care systems.

This article is protected by copyright. All rights reserved 


\section{REFERENCES}

1. OECD. Health for Everyone?: Social Inequalities in Health and Health Systems, OECD Health Policy Studies OECD Publishing, Paris2019.

2. Rigsrevisionens beretning afgivet til Folketinget med Statsrevisorernes bemærkninger. Forskelle i behandlingskvaliteten på sygehusene. København2019.

3. Pedersen KM, Andersen JS, Søndergaard J. General practice and primary health care in Denmark. Journal of the American Board of Family Medicine : JABFM. 2012;25 Suppl 1:S34-38.

4. Vanderpump MP, Tunbridge WM. Epidemiology and prevention of clinical and subclinical hypothyroidism. Thyroid : official journal of the American Thyroid Association. 2002;12(10):839847.

5. Mollehave LT, Linneberg A, Skaaby T, Knudsen N, Jorgensen T, Thuesen BH. Trends in treatments of thyroid disease following iodine fortification in Denmark: a nationwide register-based study. Clinical epidemiology. 2018;10:763-770.

6. Rasmussen LB, Carle A, Jorgensen T, et al. lodine intake before and after mandatory iodization in Denmark: results from the Danish Investigation of lodine Intake and Thyroid Diseases (DanThyr) study. The British journal of nutrition. 2008;100(1):166-173.

7. Volzke H, Craesmeyer C, Nauck M, et al. Association of socioeconomic status with iodine supply and thyroid disorders in northeast Germany. Thyroid : official journal of the American Thyroid Association. 2013;23(3):346-353.

8. Wilson S, Parle JV, Roberts LM, et al. Prevalence of subclinical thyroid dysfunction and its relation to socioeconomic deprivation in the elderly: a community-based cross-sectional survey. The Journal of clinical endocrinology and metabolism. 2006;91(12):4809-4816.

9. Carle A, Pedersen IB, Knudsen N, Perrild H, Ovesen L, Laurberg P. Gender differences in symptoms of hypothyroidism: a population-based DanThyr study. Clinical endocrinology. 2015;83(5):717725.

10. Pearce SH, Brabant G, Duntas LH, et al. 2013 ETA Guideline: Management of Subclinical Hypothyroidism. European thyroid journal. 2013;2(4):215-228.

11. Wartofsky L, Dickey RA. The evidence for a narrower thyrotropin reference range is compelling. The Journal of clinical endocrinology and metabolism. 2005;90(9):5483-5488.

12. Surks MI, Goswami G, Daniels GH. The thyrotropin reference range should remain unchanged. The Journal of clinical endocrinology and metabolism. 2005;90(9):5489-5496.

This article is protected by copyright. All rights reserved 
13. Petersen M, Knudsen N, Carle A, et al. Increased Incidence Rate of Hypothyroidism After lodine Fortification in Denmark: A 20-Year Prospective Population-Based Study. The Journal of clinical endocrinology and metabolism. 2019;104(5):1833-1840.

14. Medici BB, Nygaard B, La Cour JL, et al. Changes in prescription routines for treating hypothyroidism between 2001 and 2015 - an observational study of 929,684 primary care patients in Copenhagen. Thyroid : official journal of the American Thyroid Association. 2019.

15. Lahelma E, Martikainen P, Laaksonen M, Aittomaki A. Pathways between socioeconomic determinants of health. Journal of epidemiology and community health. 2004;58(4):327-332.

16. Galobardes B, Shaw M, Lawlor DA, Lynch JW, Davey Smith G. Indicators of socioeconomic position (part 1). Journal of epidemiology and community health. 2006;60(1):7-12.

17. Borg R, Persson F, Siersma V, Lind B, de Fine Olivarius N, Andersen CL. Interpretation of $H b A(1 c)$ in primary care and potential influence of anaemia and chronic kidney disease: an analysis from the Copenhagen Primary Care Laboratory (CopLab) Database. Diabetic medicine : a journal of the British Diabetic Association. 2018;35(12):1700-1706.

18. Jensen VM, Rasmussen AW. Danish Education Registers. Scandinavian journal of public health. 2011;39(7 Suppl):91-94.

19. Pedersen CB. The Danish Civil Registration System. Scandinavian journal of public health. 2011;39(7 Suppl):22-25.

20. Schmidt M, Schmidt SA, Sandegaard JL, Ehrenstein V, Pedersen L, Sorensen HT. The Danish National Patient Registry: a review of content, data quality, and research potential. Clinical epidemiology. 2015;7:449-490.

21. Kildemoes HW, Sorensen HT, Hallas J. The Danish National Prescription Registry. Scandinavian journal of public health. 2011;39(7 Suppl):38-41.

22. Andersen JS, Olivarius Nde F, Krasnik A. The Danish National Health Service Register. Scandinavian journal of public health. 2011;39(7 Suppl):34-37.

23. Charlson ME, Pompei P, Ales KL, MacKenzie CR. A new method of classifying prognostic comorbidity in longitudinal studies: development and validation. Journal of chronic diseases. 1987;40(5):373-383.

24. Quan $\mathrm{H}, \mathrm{Li} \mathrm{B}, \mathrm{Couris} \mathrm{CM}$, et al. Updating and validating the Charlson comorbidity index and score for risk adjustment in hospital discharge abstracts using data from 6 countries. American journal of epidemiology. 2011;173(6):676-682.

This article is protected by copyright. All rights reserved 
25. Haupt TH, Petersen J, Ellekilde G, et al. Plasma suPAR levels are associated with mortality, admission time, and Charlson Comorbidity Index in the acutely admitted medical patient: a prospective observational study. Critical care (London, England). 2012;16(4):R130.

26. Olmos RD, Figueiredo RC, Aquino EM, Lotufo PA, Bensenor IM. Gender, race and socioeconomic influence on diagnosis and treatment of thyroid disorders in the Brazilian Longitudinal Study of Adult Health (ELSA-Brasil). Brazilian journal of medical and biological research = Revista brasileira de pesquisas medicas e biologicas. 2015;48(8):751-758.

27. Mollehave LT, Linneberg A, Skaaby T, et al. Trends in Costs of Thyroid Disease Treatment in Denmark during 1995-2015. European thyroid journal. 2018;7(2):75-83.

28. Esfandiari NH, Reyes-Gastelum D, Hawley ST, Haymart MR, Papaleontiou M. Patient Requests for Tests and Treatments Impact Physician Management of Hypothyroidism. Thyroid : official journal of the American Thyroid Association. 2019;29(11):1536-1544.

29. Flynn RW, Bonellie SR, Jung RT, MacDonald TM, Morris AD, Leese GP. Serum thyroid-stimulating hormone concentration and morbidity from cardiovascular disease and fractures in patients on long-term thyroxine therapy. The Journal of clinical endocrinology and metabolism. 2010;95(1):186-193.

30. Lillevang-Johansen M, Abrahamsen B, Jorgensen HL, Brix TH, Hegedus L. Over- and UnderTreatment of Hypothyroidism Is Associated with Excess Mortality: A Register-Based Cohort Study. Thyroid : official journal of the American Thyroid Association. 2018;28(5):566-574.

31. Creed FH, Davies I, Jackson J, et al. The epidemiology of multiple somatic symptoms. Journal of psychosomatic research. 2012;72(4):311-317.

32. Erlangsen A, Fedyszyn I. Danish nationwide registers for public health and health-related research. Scandinavian journal of public health. 2015;43(4):333-339.

33. Laurberg P, Andersen S, Pedersen IB, Knudsen N, Carle A. Prevention of autoimmune hypothyroidism by modifying iodine intake and the use of tobacco and alcohol is manoeuvring between Scylla and Charybdis. Hormones (Athens, Greece). 2013;12(1):30-38.

34. Gruppen EG, Kootstra-Ros J, Kobold AM, et al. Cigarette smoking is associated with higher thyroid hormone and lower TSH levels: the PREVEND study. Endocrine. 2020;67(3):613-622.

This article is protected by copyright. All rights reserved 
Table 1: Characteristics of person years with minimum one GP-contact and TSH-measurements during 2001-2015.

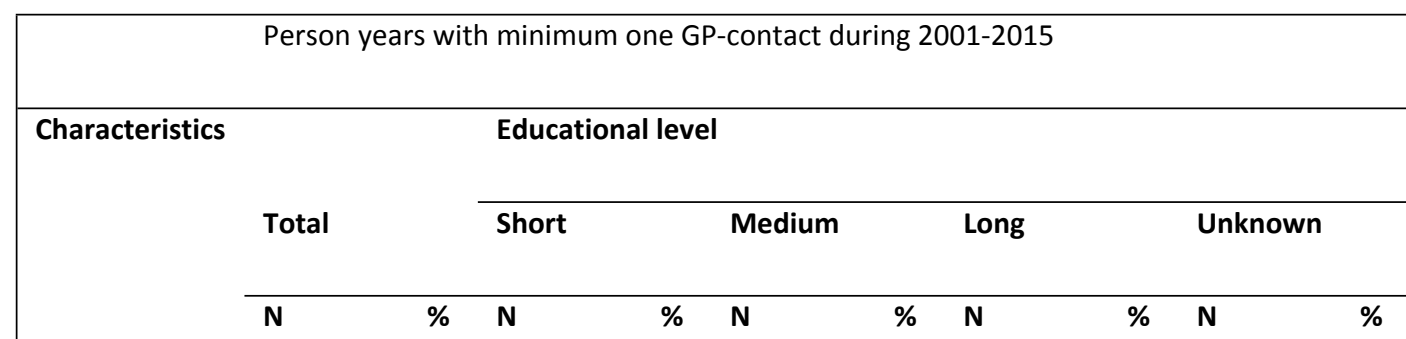

\begin{tabular}{|l|r|r|r|r|r|r|r|r|r|r|}
\hline Age & & & & & & & & & & \\
\hline $25-34$ & $2,331,684$ & 24 & 715,533 & 24 & 536,928 & 18 & $1,004,141$ & 30 & 75,082 & 15 \\
\hline $35-44$ & $2,094,423$ & 21 & 553,943 & 18 & 624,238 & 21 & 862,962 & 26 & 53,280 & 10 \\
\hline $45-54$ & $1,765,066$ & 18 & 517,813 & 17 & 579,963 & 19 & 621,700 & 19 & 45,590 & 9 \\
\hline $55-64$ & $1,553,066$ & 16 & 474,810 & 16 & 577,561 & 19 & 468,253 & 14 & 32,442 & 6 \\
\hline $65-74$ & $1,143,934$ & 12 & 412,564 & 14 & 440,556 & 15 & 255,531 & 8 & 35,283 & 7 \\
\hline $75-84$ & 715,500 & 7 & 290,131 & 10 & 230,415 & 8 & 114,683 & 3 & 80,271 & 16 \\
\hline $85+$ & 301,408 & 3 & 52,457 & 2 & 36,578 & 1 & 19,292 & 1 & 193,081 & 37 \\
\hline Sex & & & & & & & & & & \\
\hline Men & $4,471,158$ & 45 & $1,354,062$ & 45 & $1,493,336$ & 49 & $1,427,265$ & 43 & 196,495 & 38 \\
& & & & & & & & & & \\
\hline
\end{tabular}

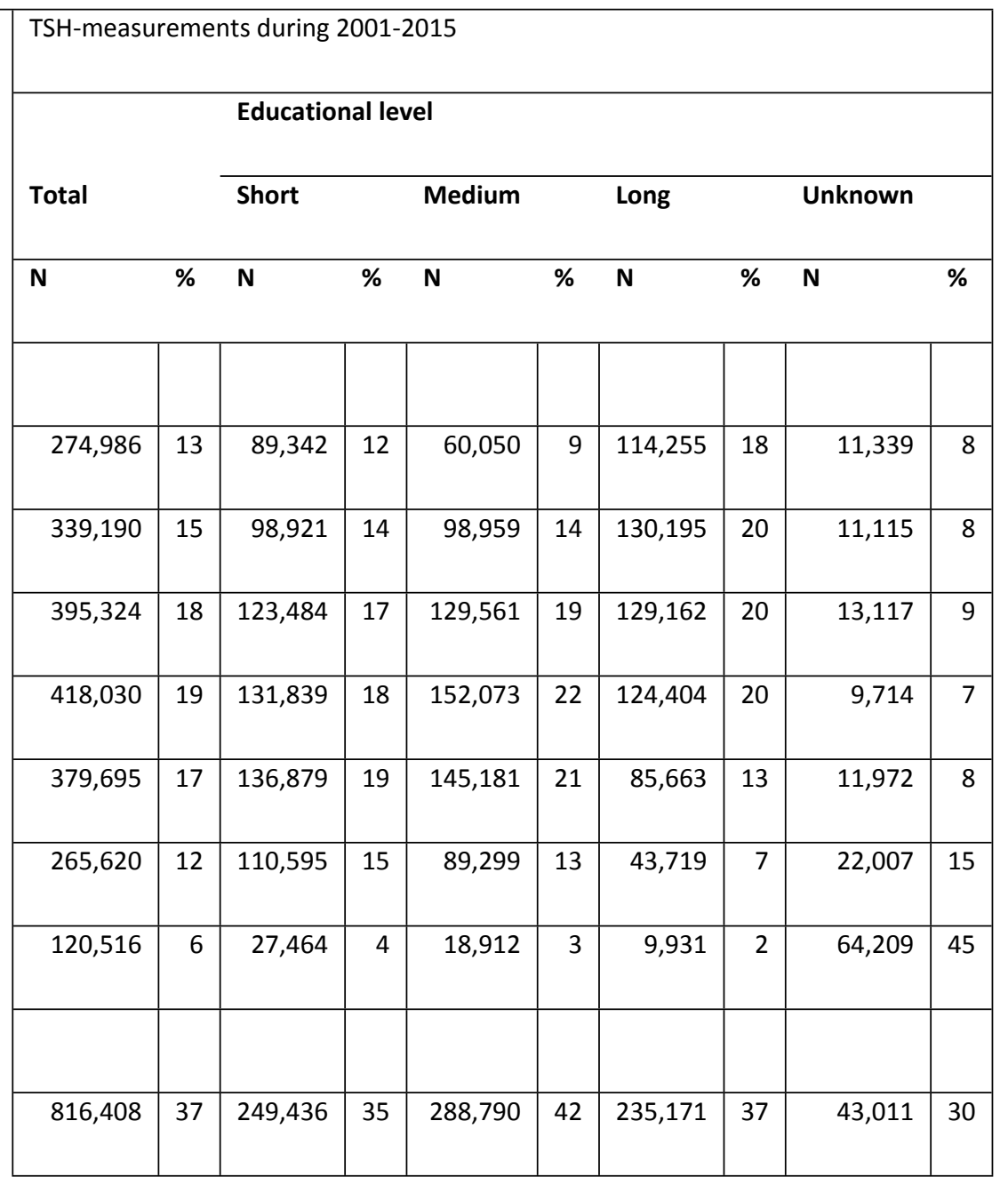

This article is protected by copyright. All rights reserved 


\begin{tabular}{|c|c|c|c|c|c|c|c|c|c|c|}
\hline Women & $5,433,923$ & 55 & $1,663,189$ & 55 & $1,532,903$ & 51 & $1,919,297$ & 57 & 318,534 & 62 \\
\hline \multicolumn{11}{|l|}{$\mathrm{CCl}$} \\
\hline 0 & $9,299,739$ & 94 & $2,789,529$ & 92 & $2,832,267$ & 94 & $3,227,630$ & 96 & 450,313 & 87 \\
\hline$\geq 1$ & 605,342 & 6 & 227,722 & 8 & 193,972 & 6 & 118,932 & 4 & 64,716 & 13 \\
\hline \multicolumn{11}{|c|}{$\begin{array}{l}\text { Number of } \\
\text { GP-contacts } \\
\text { per year }\end{array}$} \\
\hline $1-3$ & $2,469,709$ & 25 & 696,266 & 23 & 730,699 & 24 & 950,179 & 28 & 92,565 & 18 \\
\hline $4-6$ & $1,936,720$ & 20 & 552,647 & 18 & 588,760 & 19 & 715,688 & 21 & 79,625 & 15 \\
\hline $7-9$ & $1,409,320$ & 14 & 412,710 & 14 & 434,192 & 14 & 497,548 & 15 & 64,870 & 13 \\
\hline$>10$ & $4,089,332$ & 41 & $1,355,628$ & 45 & $1,272,588$ & 42 & $1,183,147$ & 35 & 277,969 & 54 \\
\hline \multicolumn{11}{|c|}{$\mathrm{TSH}, \mathrm{mIU} / \mathrm{L}$} \\
\hline$<0.4$ & - & - & - & - & - & - & - & - & - & - \\
\hline $0.4-2.5$ & - & - & - & - & - & - & - & - & - & - \\
\hline $2.5-5.0$ & - & - & - & - & - & - & - & - & - & - \\
\hline
\end{tabular}

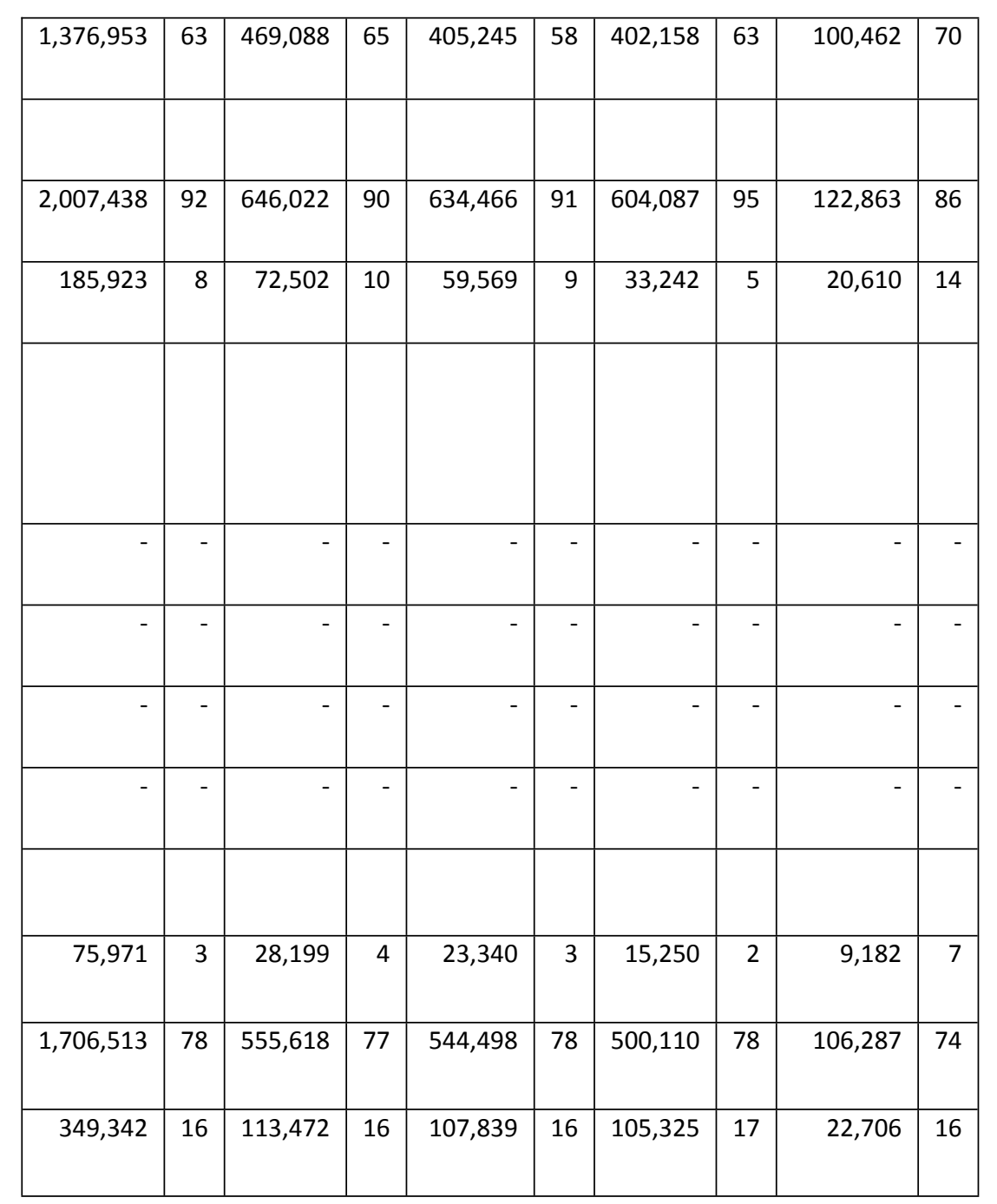

This article is protected by copyright. All rights reserved 


\begin{tabular}{|c|c|c|c|c|c|c|c|c|c|c|c|c|c|c|c|c|c|c|c|c|}
\hline $5.0-10$ & - & - & - & - & - & - & - & - & - & - & 49,826 & 2 & 17,257 & 2 & 14,806 & 2 & 13,557 & 2 & 4,206 & 3 \\
\hline$>10$ & - & - & - & - & - & - & - & - & - & - & 11,709 & 1 & 3,978 & 1 & 3,552 & 1 & 3,087 & 0 & 1,092 & 1 \\
\hline Calendar ye & & & & & & & & & & & & & & & & & & & & \\
\hline $2001-2003$ & $1,806,429$ & 18 & 607,611 & 20 & 563,249 & 19 & 479,565 & 14 & 156,004 & 30 & 248,997 & 11 & 86,675 & 12 & 74,966 & 11 & 52,144 & 8 & 35,212 & 25 \\
\hline $2004-2006$ & $1,823,708$ & 18 & 597,070 & 20 & 569,647 & 19 & 541,013 & 16 & 115,978 & 23 & 344,452 & 16 & 120,167 & 17 & 109,036 & 16 & 81,910 & 13 & 33,339 & 23 \\
\hline $2007-2009$ & $2,049,431$ & 21 & 626,545 & 21 & 635,843 & 21 & 691,824 & 21 & 95,219 & 18 & 437,606 & 20 & 147,801 & 21 & 141,893 & 20 & 120,499 & 19 & 27,413 & 19 \\
\hline $2010-2012$ & $2,083,410$ & 21 & 601,943 & 20 & 630,371 & 21 & 770,372 & 23 & 80,724 & 16 & 533,361 & 24 & 172,597 & 24 & 170,749 & 25 & 164,921 & 26 & 25,094 & 17 \\
\hline $2013-2015$ & $2,142,103$ & 22 & 584,082 & 19 & 627,129 & 21 & 863,788 & 26 & 67,104 & 13 & 628,945 & 29 & 191,284 & 27 & 197,391 & 28 & 217,855 & 34 & 22,415 & 16 \\
\hline
\end{tabular}

$\mathrm{N}$ number of observations, GP general practitioner, TSH thyroid stimulating hormone, $\mathrm{CCl}$ Charlson comorbidity index

Each person contributes person years every year with a GP-contact, i.e. between 1-15 person years.

This article is protected by copyright. All rights reserved 
1 Table 2: Relative risk for TSH-measurement

\begin{tabular}{|l|l|l|l|l|l|}
\hline Educational level & & & & \\
\hline Short & & Medium & & Long \\
\hline \% (years with TSH- & & $\begin{array}{l}\text { \% (years with TSH- } \\
\text { measurement/years }\end{array}$ & & $\begin{array}{l}\text { \% (years with TSH- } \\
\text { measurement/years }\end{array}$ & RR (95\%Cl) \\
measurement/years & total) & RR (95\%Cl) & total) & RR (95\%Cl) & total) \\
\hline $\begin{array}{l}21 \\
(632,694 / 3,017,251)\end{array}$ & $1.16(1.15-1.16)$ & $(614,387 / 3,026,239)$ & $1.11(1.06-1.12)$ & $(558,219 / 3,346,562)$ & $1($ ref.) \\
\hline
\end{tabular}

2 RR relative risk, $\mathrm{Cl}$ confidence interval

3 RR estimates from the model including educational level, sex, age, $\mathrm{CCl}$, and calendar year

5 Table 3: Relative risk of treatment initiation

\begin{tabular}{|c|c|c|c|c|c|c|}
\hline & $\begin{array}{l}\text { Educational } \\
\text { level }\end{array}$ & & & & & \\
\hline & Short & & Medium & & Long & \\
\hline TSH, mIU/L & $\begin{array}{l}\% \text { (treatment } \\
\text { initiation/TSH- } \\
\text { measurements) }\end{array}$ & $\mathrm{RR}(95 \% \mathrm{Cl})$ & $\begin{array}{l}\text { \% (treatment } \\
\text { initiation/TSH- } \\
\text { measurements) }\end{array}$ & RR $(95 \% \mathrm{Cl})$ & $\begin{array}{l}\% \text { (treatment } \\
\text { initiation/TSH- } \\
\text { measurements) }\end{array}$ & $\mathrm{RR}(95 \% \mathrm{Cl})$ \\
\hline$<0.4$ & $\begin{array}{l}0.63 \\
(179 / 28,199)\end{array}$ & $0.47(0.39-0.57)$ & $\begin{array}{l}0.65 \\
(152 / 23,340)\end{array}$ & $0.48(0.39-0.59)$ & $\begin{array}{l}1.59 \\
(242 / 15,250)\end{array}$ & 1 (ref.) \\
\hline $0.4-2.5$ & $\begin{array}{l}0.06 \\
(309 / 555,618)\end{array}$ & $0.78(0.67-0.91)$ & $\begin{array}{l}0.05 \\
(259 / 544,498)\end{array}$ & $0.69(0.59-0.80)$ & $\begin{array}{l}0.08 \\
(403 / 500,110)\end{array}$ & 1 (ref.) \\
\hline $2.5-5$ & $\begin{array}{l}0.29 \\
(333 / 113,472)\end{array}$ & $0.57(0.50-0.66)$ & $\begin{array}{l}0.27 \\
(289 / 107,839)\end{array}$ & $0.54(0.47-0.62)$ & $\begin{array}{l}0,19 \\
(610 / 105,325)\end{array}$ & 1 (ref.) \\
\hline $5-10$ & $\begin{array}{l}16.22 \\
(2,799 / 17,257)\end{array}$ & $0.96(0.91-1.00)$ & $\begin{array}{l}17.10 \\
(2,532 / 14,806)\end{array}$ & $1.01(0.96-1.06)$ & $\begin{array}{l}19.49 \\
(2,642 / 13,557)\end{array}$ & 1 (ref.) \\
\hline$>10$ & $\begin{array}{l}56.44 \\
(2,245 / 3,978)\end{array}$ & $1.07(1.02-1.12)$ & $\begin{array}{l}57.85 \\
(2,055 / 3,552)\end{array}$ & $1.08(1.03-1.13)$ & $\begin{array}{l}62.94 \\
(1,943 / 3,087)\end{array}$ & 1 (ref.) \\
\hline
\end{tabular}

$6 \mathrm{RR}$ relative risk, $\mathrm{Cl}$ confidence interval

7 Joint effect RR estimates from the model including educational level, sex, age, TSH-level, calendar year,

8 and the interaction between TSH-level and educational level

This article is protected by copyright. All rights reserved 


\section{Figure legends}

11 Figure 1: Flow chart of in- and excluded observations for analyses of a) the association between

12 educational level and TSH-measurement, and b) the association between educational level initiation of

13 levothyroxine treatment.

14 GP general practitioner, CC and CM Copenhagen County and Copenhagen Municipality, CGPL Copenhagen

15 General Practitioners' Laboratory, TSH thyroid stimulating hormone

16 Figure 2: Relative risk and 95\% confidence intervals for TSH-measurement for short and medium

17 education compared with long education within each 3-year period. Joint effect RR estimates from the

18 model including educational level, sex, age, $\mathrm{CCl}$, calendar year, and the interaction between educational

19 level and calendar year.

20 RR relative risk

21 Figure 3: Relative risk and 95\% confidence intervals for treatment initiation for short and medium

22 education compared with long education within each 3-year period. Joint effect RR estimates from the

23 model including educational level, sex, age, $\mathrm{CCl}$, TSH-level, calendar year, and the 3-way interaction

24 between educational level, TSH-level, and calendar year

25 RR relative risk, TSH thyroid stimulating hormone

This article is protected by copyright. All rights reserved 
a)

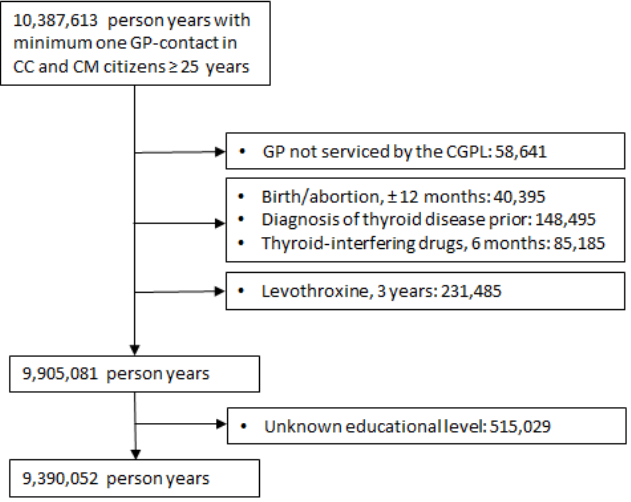

b)

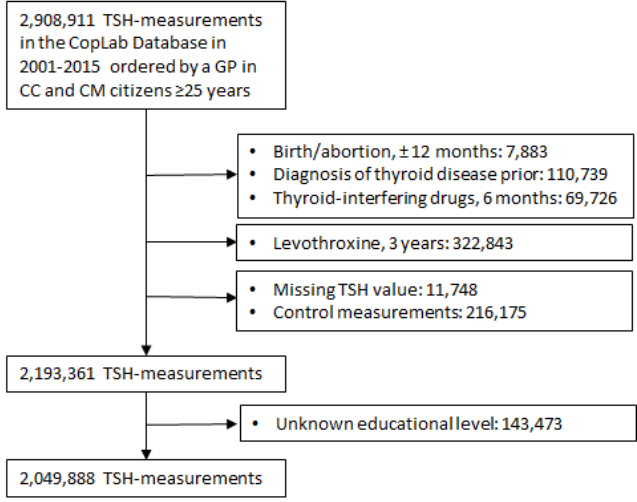

cen_14429_f1.tif 


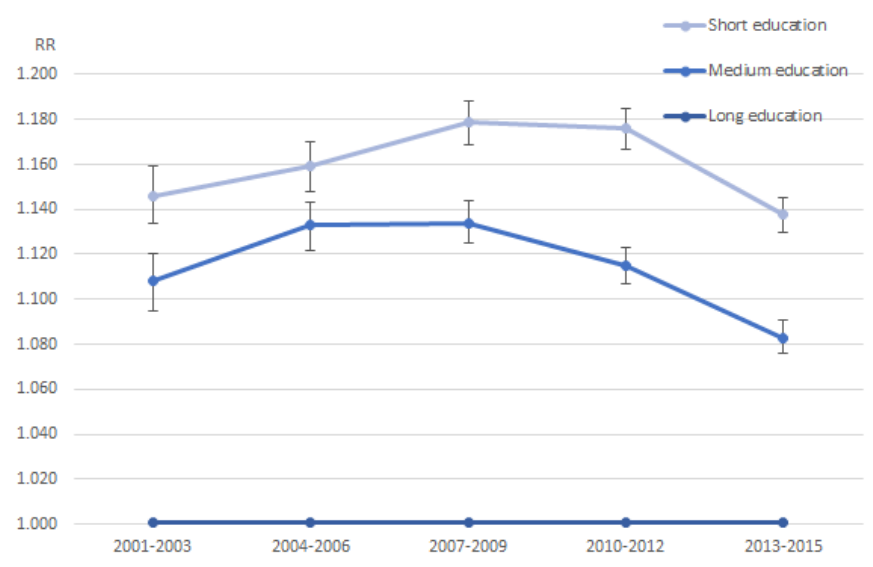

cen_14429_f2.tif

This article is protected by copyright. All rights reserved 


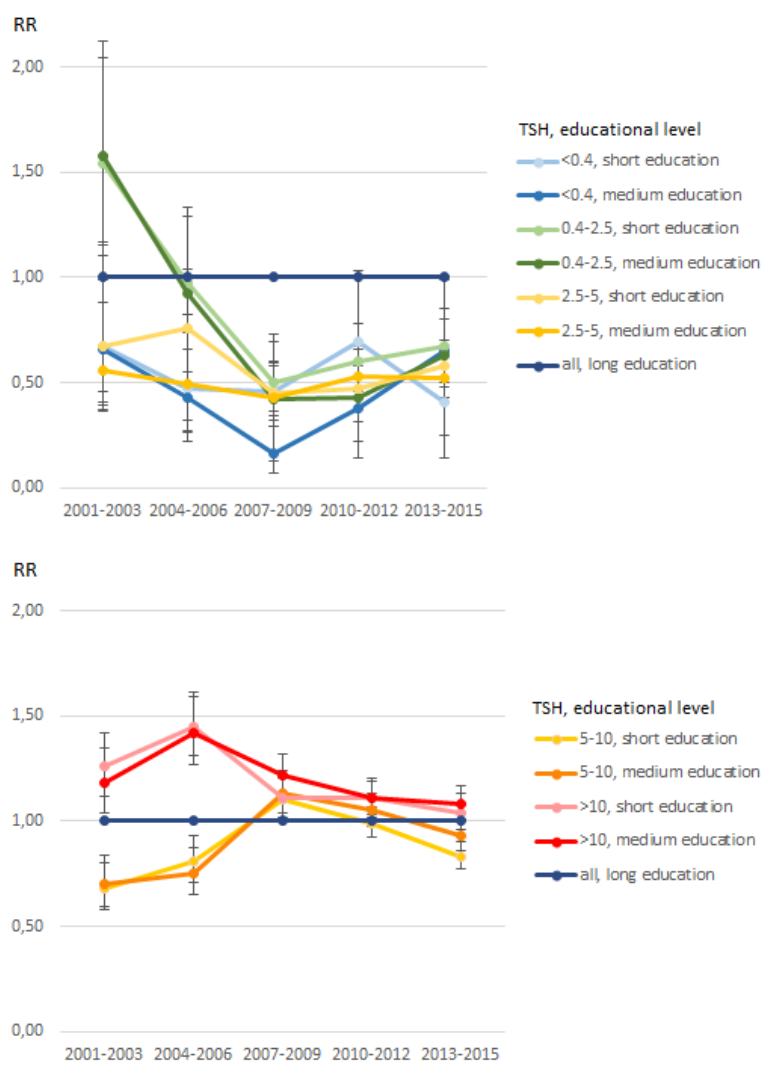

cen_14429_f3.tif

This article is protected by copyright. All rights reserved 